\title{
Life after \#MeToo: Understanding the Impact of Adolescent Sexual Assault on Education and Career
}

\author{
Andrea Nikischer \\ SUNY Buffalo State \\ Buffalo, NY 14222
}

\begin{abstract}
This article tells the story of four adult women whose lives and educational journeys were impacted by sexual violence during adolescence. Through in-depth interviews and a focus group these women reflect on the ways that sexual violence impacted their lives as learners and changed their life course. Their stories support and extend previous research that indicates that sexual assault during adolescence negatively impacts academic achievement and alters career and life goal-setting. Importantly, participants in this study perceive that elementary and secondary schools are failing girls on the issue of sexual violence, and in some cases are causing survivors additional harm. The presentation of findings is "data heavy" as it is the survivors own words which most accurately describe the impact of sexual violence on the lives of women.
\end{abstract}

Keywords: career choice/development; education; emerging adulthood; qualitative research; sexual violence.

\section{Introduction}

In September 2018, the United States was captivated by the confirmation process for a new Supreme Court Justice. Millions of Americans tuned in to watch the U.S. Senate hearing in which a sexual violence survivor, Dr. Christine Blasey Ford, shared her experience of sexual assault while in high school. The man she believes committed the assault was the same man hoping to be appointed to the nation's highest court: Judge Brett Kavanaugh. Ford's testimony led to an outpouring of stories from survivors of sexual violence across the country once again thrusting the issue of sexual assault back into the national spotlight. The Kavanaugh hearing took place just under one year after widespread accusations of sexual assault against Hollywood executive Harvey Weinstein inspired the \#MeToo movement. That movement encourages women to share their stories of sexual harassment and sexual assault via the online \#MeToo hashtag. Prior to the Weinstein scandal the U.S. confronted a year of revelations of pervasive sexual harassment in the media and politics, including the release of the famed 
Access Hollywood tape in which future U.S. President Donald Trump bragged about kissing and groping women against their will. Through each of these seemingly "watershed" historical moments one thing has become very clear: sexual violence is an epidemic in the United States.

Previous research has found that over $18 \%$ of women in the U.S. are survivors of sexual assault, and nearly half of those women (42\%) were sexually assaulted before the age of 18 (Black et al 2011, p. 2). Data from the 2011 United States Youth Risk Behavior Surveillance (YRBS) study found $11.8 \%$ of female students responded "yes" to having been physically forced to have sexual intercourse when they did not want to (Centers for Disease Control and Prevention 2012). Because a large number of adolescent girls experience sexual assault, it is important to understand the impact of sexual violence on a survivor's life. A majority of survivors experience symptoms of Post-Traumatic Stress Disorder (PTSD), such as intrusive memories, avoidance behaviors and anxiety/hypersensitivity, immediately following the assault, and nearly onequarter of survivors continue to experience symptoms of PTSD years later (Koss, Heise and Russo, 1997). Survivors are also at risk for serious depression, suicidal ideation and suicide, low self-esteem, substance abuse and eating disorders (see Black et al, 2011; Ullman and Najdowski, 2009; Yuan, Koss and Stone, 2006).

The specific impact of sexual abuse during childhood and adolescence on development and well-being during emerging adulthood (ages 18-29; see Arnett, 2000) has been studied. Fergusson, Boden and Horwood (2008) analyzed 25 years of longitudinal data from the Christchurch Health and Development Study (CHDS) in New Zealand and found that sexual abuse before the age of 16 "was consistently related to mental health problems in adolescence and young adulthood" (p. 617). In fact participants who experienced "completed or attempted penetration" prior to age 16 had rates of disorder- including depression, anxiety, suicidal ideation/attempt and substance dependence- that were 2.4 times higher than participants who had not experienced sexual abuse. Fergusson, McLeod and Horwood (2013) later studied 30 years of the CHDS data and found that child sexual abuse continues to adversely impact development- including mental and physical health - through to age 30.

Beyond mental and physical health, sexual assault during adolescence can impact a survivor's education and career. Albaugh \& Nauta (2005) found that among adult women, sexual coercion is negatively associated with three aspects of career decision self-efficacy, even after controlling for symptoms of depression. "Sexual coercion was significantly negatively associated with participants' confidence in their ability to engage in accurate self-appraisal, their ability to select goals, and their ability to problem solve when faced with career decision-making challenges" (p. 296). Through a quantitative survey study of 18 and 19 year-olds in Norway, Huang and Mossige (2012) found that the experience of sexual abuse before the age of 13 has a strong negative effect on educational achievement. In a qualitative study of adult literacy practitioners in Canada, Too Scared to Learn, Horsman (2000) also concluded that a history of interpersonal violence can negatively impact educational outcomes for adults. In a later piece, Horsman (2006) argued that a history of violence can make students feel that they are "too stupid" to learn. It is this aspect of the impact of sexual assault- the focus on education and career- that drove my research. 


\section{Research Methods \& Data Analysis}

Through qualitative interviews I sought to explore female survivors' perceptions of how the experience of sexual violence during adolescence impacted their lives in the context of education and career. I utilized the following research question to guide the work: How do survivors reflect back on their experiences with sexual violence, and in what ways do they perceive that the experience with violence has impacted their educational outcomes and life choices?

\section{Theoretical Framework}

As approximately 9 out of 10 survivors of rape are female (United States Department of Justice, 2003), this study deliberately gives voice to women and validates their perspectives. Using feminist theory (see Olesen 2011) as a frame, I explored the long-term impact of the oppression of women through sexual violence by men. While important quantitative research has been conducted about sexual assault, this qualitative study privileges the voices of the female survivors. McMahon (2014) declared the need for more "qualitative and personoriented research" illustrating the potential impact of childhood maltreatment on development during emerging adulthood. Here the survivors are not merely participants; they are partners in the research, telling their own life stories in their own words. The presentation of findings is deliberately and importantly "data heavy," as it is the voices of the survivors which advance our knowledge about the impact of sexual violence on the lives of women.

\section{Participants}

Four adult women who were sexually assaulted while they were under the age of 18 participated in the study. The participants were white, between the ages of 23-38, and from lower-middle to upper-middle class backgrounds. They were recruited from the community using a variety of methods, including marketing through community service agencies and university listservs. Participants took part in both an informed consent process and a post-interview de-briefing session. All of the women indicated that they chose to participate in order to allow their personal story to "help."

\section{Interviews}

Two qualitative research methods were utilized for this research study: in-depth individual interviews and a focus group interviewi. Each participant took part in a lengthy face-to-face semi-structured individual interview. "The purpose of the qualitative research interview is to contribute to a body of knowledge that is conceptual and theoretical and is based on the meanings that life experiences hold for the interviewees" (DiCicco- Bloom, \& Crabtree, 2006, p. 314). The indepth interviews allowed enough time for the participants and I to work together to unravel and examine the complex layers of issues that result from sexual assault. Through interviews that were deliberately constructed to invite deep reflection of the past, participants were asked to consider the moment(s) of their life before, during and after the adolescent sexual assault. In so doing participants were able to narrate who they believed themselves to be before the violence and their story of who they became after. 


\section{Focus Group}

In Focus Groups in Feminist Research, Madriz (2000) lays out several compelling arguments for the use of focus groups. "Women have historically used conversation with other women as a way to deal with their oppression." (p. 839). The collective interaction that focus groups provide serves to validate the experiences of participants in a way that individual interviews cannot. One focus group was conducted as part of this research study, including two participants who were survivors of a single sexual assault during adolescence.ii While a two-person focus group is small, the women worked closely together and built a strong rapport.

\section{Data Analysis}

I began the qualitative data analysis by reading though one quarter of the interview transcripts and establishing categories for coding. All qualitative interview data were then coded by hand. Coded segments were exported and placed in appropriately labeled digital folders by code. I then read each transcript thoroughly, as well as all data in each coding file, to begin to construct my findings (see Weis and Fine, 2000). After completing the interview coding and initial analysis, I held the focus group interview. In the interview I asked participants about the initial themes I had identified to confirm they were a genuine representation of their experiences. This form of "member checking" (see Lincoln \& Guba, 1985) is an important step in ensuring the stories of the female survivors are accurately told.

\section{The Survivors}

\section{Sara}

When we met Sara was 26 and living with her parents in a large home in an affluent neighborhood of the city.iii She was warm and affable, and open to talking about the many struggles she had faced in her young life. As a single mother, Sara related that her focus is on caring for her 5 year-old son whom she credits for "saving" her.

Sara: [After the rape] Everything changed... I quit sports. I did not do anything after school... I think I was just so, wanting to hide away almost. I didn't want to be involved. I know it sounds so over the top, but literally everything frightened me to the point of small, things, small, small things. I used to be very much a daredevil almost. I would have tried anything. And then I was frightened of life.

When Sara was 15, she snuck out of her house to attend a party down the street. On the way home, she was raped in a neighbor's yard by an acquaintance. The day after the assault the course of her life began to change. She relates that her dreams of becoming an actress were replaced by an obsession with suicide and death. Her grades at her elite private high school dropped from As and Bs, to Ds and Fs. She abandoned her extra-curricular activities and focused her life on "hiding away."

Sara: In high school I could have given two craps about anything they were teaching. I thought it was all BS. I want to die tomorrow, why do I need to know who was our first, second, third president? I had a very negative attitude toward education [after the sexual assault]... 
Like all four women in this study, Sara narrated significant changes in her engagement with school after the sexual violence. The assault left Sara only feeling safe when she was at home, which, in turn, caused her to drop out of soccer and her other extra-curricular activities. For Sara life became focused on maintaining the eating disorder that began the morning following her assault, and on her fixation with suicide. These unhealthy behaviors became her mechanisms for coping with feelings of pain and fear.

Sara: My grades afterwards [after the rape], sophomore year, were horrible, absolutely horrible. I remember getting Ds and Fs throughout the year... I also, educationally, had so many goals beforehand. I was so into school. I was very much into learning and all of that changed drastically.

Ultimately, Sara's grades in school declined to the point where she was concerned that she that she would not be able to graduate. While she was able to finish high school, during the years following she continued to struggle with anorexia and bulimia, ultimately having to attend in-patient treatment to save her life. A few months after the rape Sara entered a serious relationship with a man that was both abusive and controlling. They stayed together for several years until Sara was able to break free after the birth of their son. Like many women in the study who were battling serious depression and suicidal ideation, planning for the future was not a priority for Sara after the sexual assault. She simply did not see a future at all, so she did not pursue long-term plans.

Sara: [After the rape] I didn't see any future. I did not see anything after tomorrow. It was really a day to day thing... All of my poems were about suicide, all my poems. One was all about how I was broken up inside, and my insides were just broken glass. I wish I could bleed, bleed until I die.

AN: So your dreams of being an actress were...

Sara: Were gone, were non-existent.

\section{Debbie}

I had the opportunity to engage with both Sara and Debbie during an individual interview and a focus group interview. In both interview settings, 30 year-old Debbie was thoughtful and reserved. Having had limited opportunities to discuss the impact of violence on her life prior to our meetings, she moved slowly and methodically through the questions. Like Sara, Debbie was living at home during the time of our interviews. She was working full-time as an administrative assistant and recently began attending school at night to become a graphic designer.

Sara: I always was a good student until after the [sexual] assault. I didn't care anymore. I was emotionally spent. Everything in life just seemed so trivial.

AN: Debbie you are nodding your head, did you have the same experience?

Debbie: Yeah.

Sara: Whether I get a good grade on a high school quiz is absolutely irrelevant to me when I am thinking about going home and slitting my wrists. 
Debbie: Yeah, yeah.

In the focus group, Debbie and Sara worked together to think through the meaning of their experiences and they provided each other with support and encouragement throughout the process. During the individual interviews all four participants in the research study expressed regret and sadness over what they feel were periods of their life after the sexual violence where they either made bad decisions or no decisions at all, particularly as related to education and career. Debbie and Sara discussed this concept of "lost years" as part of the focus group interview.

Sara: Well I've always thought of that term, as in I, for so many years, eight or nine after I was raped, I feel like all those years were all lost years. As in I wasn't living, I wasn't engaging in life, because I was so frightened to live. And my relationships, with guys and girls, were so altered because of the way I felt about myself because of what happened. So I feel like I couldn't achieve what I wanted, I couldn't be my best self, and you wake up and you are 25 years old and you're like, "God, I wish I had had the esteem to do this or that," but it's done.

Debbie: I just now feel like I'm getting my life on track. This happened when I was 16 years old and I'm almost 30, so how many years later. I had given up on education and a career, and basically I feel like the past, how many years I have wasted. Not just lost, but wasted. I feel like there is so much more I could have done, could be doing.

Similar to Sara, Debbie was raped by an acquaintance at a party at a friend's house when she was 16. After the assault her life began to spiral downward. She fell into deep depression and became distracted by thoughts of suicide. Debbie was accepted into the top ranked high school in her city, but she experienced a severe decline in grades after she was raped and a major shift in her engagement with school. Her grades dropped from Bs, to Ds and Fs after the assault, and her dream of becoming a writer or editor "died."

Debbie: That's when I started drinking more and started experimenting with drugs and really stopped caring about school...I didn't trust myself anymore, that I knew what I wanted, that I could even do it, that I could graduate high school. I didn't know that I could get accepted to a college, so in a way I basically gave up. I was just like I don't really want to think about it, so I just won't.

AN: So prior to the sexual assault you were getting Bs, doing well in school, going to school, and after the sexual assault? What were your grades like?

Debbie: I failed biology. I failed chemistry. I had to repeat chemistry. I had to go to biology summer school...I wasn't participating in class anymore...I really just quit trying without realizing it.

Debbie perceives that the assault led her to "give up" on her school work. After the assault and into her mid-20's, Debbie used, and often times abused, alcohol and other drugs.

AN: Did your goals change after the sexual assault?

Debbie: I didn't have goals anymore...I gave up. I just let life happen to me. 
As a student in the city's gifted and talented public high school, Debbie's dreams were well within her reach before the sexual assault. However, she stopped having goals for the future after she was assaulted. Her decline in grades, combined with her lack of confidence in her own ability to make decisions, drastically changed the trajectory of her life.

Debbie: I really do feel that if that [the sexual assault] had not happened to me, and I had kept on the course I was on, I would be a completely different person right now...I think of where I am now and I feel like a failure, a big time failure. I'm embarrassed to see people from high school, because I feel like "This is my life?"

\section{Kim}

Kim and I met when she was 32 years-old living in the suburbs with her new husband. Kim had recently returned to school and was pursuing a graduate degree in counseling. We met at her home as she did not feel safe going out after dark. Every light in her home was lit and her dog sat by her side throughout the interview.

Kim: The worst part about sexual abuse is that you feel so alone. I'm like this freak who is branded for life and I'm never going to be ok.

Kim survived several incidents of child sexual abuse and incest at the hands of three different perpetrators, beginning at the age of four and ending in her midteens. She spent her life battling depression and suicidal ideation, and became involved in "cutting" in her late teens. Kim believes the sexual abuse negatively impacted her academic achievement in middle school, high school and college.

Kim: So the next year I went off to law school. I was far away from home and I was living with a roommate at that time and she got a job where she was sleeping over there; it was like a night thing. So I was completely alone in the house at night, which is my scariest time. All I can say about it is it is very difficult to study when you are pushing a dresser in front of your door because you are so afraid.

Kim experienced periods where her grades declined drastically in middle school, high school and during her undergraduate studies. She attributes these periods of decline to bouts of depression, anxiety and "zoning out" in the aftermath of her experiences of child sexual abuse. Although she was able to go to summer school and a community college to bring up her grades and get back on her original path, her battle with post-abuse fear eventually forced her to drop out of law school, ending her dream of becoming a judge.

My last semester there, which was about a year and a half into it, I walked in to the final exam and I just started crying. I just started crying and I decided its ending right here. I decided not to take it. I didn't even go to the other finals. I don't know how I would have done, but I just started crying and I couldn't stop. I was like, "Nothing is worth this." It was a breakdown. I had a breakdown and so I quit school.

Like Sara and Debbie, Kim expressed that the sexual abuse experienced led to a period of wasted or lost years in her life. These lost years impacted her education and career outcomes, and life direction.

Kim: It's something I'm always saying. What I notice is when people ask me about my life, back then I never talked about anything but my 
friends, I never talked about anything about me. I never talked about my home or anything like that. Why? The first 28 years of my life were shit. They were a waste.

Jane

When we met, Jane was 36 and had recently returned to school to pursue a degree in psychology. She has a strong presence and is passionate when she speaks about her experiences with sexual assault and abuse. Our discussion went one for many hours, as we worked together to unravel the complex experiences of her childhood and adolescence.

Jane: School became my saving grace. I couldn't wait to go to school in the morning and I would drag heels on the way home. [Before the sexual abuse] I loved school. I loved to learn. But then I only wanted to go to school to not be at home.

AN: So the love of learning was gone now [after the sexual abuse began]? Jane: Yes.

Jane was physically and sexually abused by her stepfather from age eight through age 17. Her experience indicates that engagement with school does not always decrease due to sexual assault. When Jane was a child, school became a refuge to escape the sexual abuse at home. While she did not have the same love of learning after the abuse began, she viewed her elementary school as the only "safe" place in her world and her engagement with school increased. Sadly for Jane, her view of school as a safe place was destroyed when she was gang raped on the grounds of her middle school after a sporting event at the age of 13 . The three perpetrators in that attack were students at her school who continued to harass and bully her throughout her secondary education.

AN: After the rape, did your activities change?

Jane: Soccer and Floor Hockey were no more.

AN: Did you quit because of the assault?

Jane: I was becoming more closed. Being around all those people I couldn't handle anymore...I spent most of my time in my bedroom now. School was no longer a safe place... My grades went from As and Bs to Cs and Ds.

After the rape, Jane's engagement with school decreased significantly. She dropped out of sports and her grades declined. With her safe place gone, her life became consumed by fear.

Jane: I didn't know how I would die, at whose hands, but I knew I would be dead by 18. That was the cut off.

AN: So future goals weren't even an option?

Jane: No.

AN: Did you plan on going to college after high school?

Jane: Hell no. I was going to die by age 18. I certainly wasn't going to college.

Convinced that she would die by the time she was 18, Jane never made any plans for the future. She struggled with anxiety, depression and alcohol abuse throughout her teens and into her late 20's. Similar to the experiences of Sara, Debbie and Kim, Jane perceives that the sexual abuse and sexual assault lead to "lost years" of her life. She believes that over two decades of her life were lost to the aftermath of sexual violence. 
Jane: I never saw a place where I was going to be ok again. I figured ok, this is my life now. This is my life...I just didn't see any kind of light at the end of the tunnel. There was just no hope.

\section{Discussion}

\section{Perceived Failure of Schools}

One theme that carried through all of the interviews was the anger and frustration that all of the women expressed toward their elementary and secondary schools. Each of these women perceive that their schools, and the teachers, counsellors and administrators within those schools, failed to prepare them to deal with sexual violence, and failed to appropriately assist them after they were sexually assaulted.

Sara: You are in such despair and no one is helping you, and even when my grades are slipping and I said I'm so depressed, and I hand in a poem about how my insides are broken glass and I want to bleed until I die, the paper got handed back to me and the teacher told me I had to revise it because it was too dark to hang for parents' night.

Debbie: How could they have known all of that and not asked?

Sara: Well that's why I hate my high school...I feel like sending them a bill for my therapy.

Despite the fact that all U.S. teachers are Child Abuse Mandated Reporters and that all certified teachers in New York State, where three of the four participants attended K-12 school, must attend a minimum two-hour Child Abuse and Neglect training (New York State Education Law, 1989), none of the women in the study believe that they were asked appropriate questions about sexual assault/sexual abuse by their teachers, and none of the teachers or school officials discussed appear to have recognized and/or appropriately acted on the warning signs exhibited by children or adolescents experiencing sexual violence. Jane: There was nothing that anyone at my school did to make it better. Believe it or not, in high school I did try to tell my gym teacher. So I would stay sometimes after class and talk to her. I'd say things like "You know, things aren't always what they seem to be." I'd try to take it down that road, but...I think she didn't want to go there, because that would open up a whole can of worms that she wasn't ready to deal with.

Both of the participants that were survivors of long-term child sexual abuse believe that if their schools had created a safe space for them to talk about abuse, or if their teachers had asked them the "right" kinds of questions, they would have disclosed the abuse and it would have ended much earlier than it did, in some cases, sparing them many years of additional violence.

Beyond failing to help, all four of the women in the study indicated that their schools (teachers, counsellors, administrators) actively did things that had a negative impact on the healing process. These survivors perceive that the administrators and staff at their schools were either ignorant of or indifferent to the needs and concerns of victims of sexual violence.

Sara: So the college counsellor confronted me the Monday after [the rape], when I got dropped off at school. She was waiting outside for me. She confronted me in a very abrupt "Why didn't you go to the police? Why didn't you tell your parents then? Why would you say something 
like this and not follow-up with it, not follow through?" She was very accusatory and very unsympathetic.

Sara's experience seems to support the findings of Kushmider, Beebe, and Black (2015) that counsellors-in-training tend to endorse certain "rape myths" and require more training specific to addressing sexual assault. For Sara, the accusatory questions asked by her counsellor confirmed the feelings of selfblame and guilt that she was already struggling with.

Kim: I think that any kind of school therapy would have been a good thing, but I don't think it was a good idea to do it in the middle of the day like that. You are asking me to bring up all this shit and then go back to class. Come on, that's not realistic.

In addition to problems with the appropriateness of the actual counseling services offered at the school, both Kim and Jane spoke about the ways in which the logistics of school counseling were inappropriate for a student dealing with issues related to sexual abuse. Their experiences illustrate the ways in which the configuration of the office space, the gender of the counsellor, and the time of the counseling appointment can have a detrimental impact not only on the counseling experience, but on the survivor's healing process.

Jane: They tried to connect me with the school psychologist, and he was this dude who knew nothing. They are going to close me into a small office with a guy I don't know? So I sat there and he's like, "Don't you want to say anything?" And I didn't answer. I did not say a word for the whole hour. And I was called out of class for this, so all the kids knew exactly where I was going.

Beyond the individual actions (and inactions) of teachers, counsellor and administrators, all four participants in the study described overarching school climates which were hostile toward women, and discouraged healthy discussion about sex and sexual violence. For these survivors, the climates of their schools acted to reinforce their feelings of powerlessness and shame after the sexual violence.

Sara: We never talked about sexual violence [at my high school]. In fact, there was a very macho attitude there. They praised the hockey players, the jocks. You know, you just got the impression of when guys would act a certain way towards girls that was inappropriate in passing in the halls, it was "Boys will be boys. Why are you bringing attention to this? Why do you want to be negative in a school that is so positive?" My school didn't talk about "dirty" things such as assault, such as incest, such as sex before marriage. If you talk about it, it brings attention to it. No one talked about it at all. We weren't allowed to.

\section{Implications for Educators}

Ultimately, all of the participants in this research study believe schools need to make positive changes to actively and appropriately address sexual violence and assist student survivors.

Sara: The school gave me nothing and I really think they should have provided a safe place at least to know that I could have gone and talked to someone that would have been confidential. 
The participants in this study believe that schools are in a unique and important position to help children and adolescents. They recognize that schools may be the only contact point outside of the home for young survivors of sexual violence. As such, they are ethically bound to prioritize the issue of sexual assault awareness and response.

Kim: I think that would have been particularly helpful at those ages if they [school teachers/staff] had told me, "You're not damaged goods. You are still a human being, and a woman, and nobody can tell [that you were sexually abused]."

It is true that schools are increasingly being asked to do more with less. So how can schools and educational policy makers decide if sexual violence is in fact an issue worth expending valuable resources of time and money on? They need look only to the law. Schools are already required to address the issue of sexual violence. As mandated reporters, all teachers, counsellors and administrators are required to understand the warning signs and to know how to respond. Ensuring that schools are motivated to identify and respond to abuse, that the process is easy, straightforward, and in no way punitive to those who respond, is critical. Sexual assault response and identification must become recognized as a major professional responsibility of all faculty and staff at K-12 schools.

\section{Sexual Assault and Emerging Adulthood}

One of the most salient findings in this study is the ways in which sexual assault during adolescence negatively impacts development through emerging adulthood. The four women featured in this paper relate that their experiences with post-assault depression, fear and low self-esteem impaired their ability to make decisions immediately following the sexual violence and through emerging adulthood. For these women emerging adulthood became a "lost" or "wasted" period of their life. It is this language of grief (loss) and regret (waste) which is most powerful for researchers and educators to understand. Sexual violence during adolescence does not just negatively impact adolescence; the impact carries on throughout emerging adulthood significantly changing the life course of female survivors.

Previous research has sought to quantify the financial cost of victimization. In an important study projecting the long-term financial costs of violent victimization, Macmillan (2000) found that violent victimization during adolescence negatively impacts earnings later in life. This negative impact appears to be due to disruptions in education and career attainment postvictimization. Findings by Fernandez et al. (2015) support Macmillan's work. Their research results indicate that childhood victimization (including sexual abuse) leads to lower income and job "prestige" growth during emerging adulthood. Their findings also indicate that this disparity in growth is due to lowered educational attainment among survivors.

But what about the societal cost? As millions of women in the United States are survivors of sexual violence we must consider how a void in development during adolescence and through emerging adulthood might potentially impact the representation of women in the highest levels of education, business and politics. One can imagine that it is difficult for women to break glass ceilings 
when they are one or two decades behind their male peers in working toward education and career goals, or when they have given up on their goals altogether. This important question must be examined in future research.

\section{Summary and Conclusion}

The stories of victims and survivors of sexual violence across the United States have captured the nation's attention. While awareness of the extent of the existence of sexual violence is an important first step in addressing that violence, we also need to understand the myriad short and long term impacts on the lives of survivors. We need to understand what happens after the violence. This research study provides us insight in to the specific impact of sexual assault on educational outcomes and career goal-setting of women after the assault and through emerging adulthood. The findings are clear: sexual assault during adolescence has the power to radically alter a woman's life.

The narrations of the survivors in this study indicate an urgent need to conduct additional qualitative research about the long-term impact of sexual violence on the lives of both women and men. Further, we must carefully consider what roles K-12 schools, post-secondary institutions and adult education programs can and should play in preventing and responding to such violence and abuse.

\section{References}

Albaugh, L. M., \& Nauta, M.M. (2005). Career decision self-efficacy, career barriers, and college Women's experiences of intimate partner violence. Journal of Career Assessment 13 (3): 288-306. https:// doi.org/10.1177/1069072705274958

Arnett, J.J. (2000). Emerging adulthood: A theory of development from the late teens through the twenties. American Psychologist 55 (5): 469-80. https://doi.org/10.1037//0003-066x.55.5.469

Black, M., Basile, K., Breiding, M., Smith, S., Walters, M., Merrick, M., Chen, J. and Stevens, M. (2011). The national intimate partner and sexual violence survey: 2010 summary report. National Center for Injury Prevention and Control, Centers for Disease Control and Prevention. Atlanta: GA.

Centers for Disease Control and Prevention. (2012). Surveillance Summaries. MMWR 2012:61 (No. SS-4).

DiCicco- Bloom, B., \& Crabtree, B. F. (2006). The qualitative research interview. Medical Education, 40(4), 314-321. https://doi.org/10.1111/j.1365-2929.2006.02418.x

Fergusson, D. M., Boden, J. M., \& Horwood, L. J. (2008). Exposure to childhood sexual and physical abuse and adjustment in early adulthood. Child Abuse \& Neglect 32 (6): 607-19. https:// doi.org/10.1016/j.chiabu.2006.12.018

Fergusson, D. M., McLeod, G. H., \& Horwood, L. J. (2013). Childhood sexual abuse and adult developmental outcomes: Findings from a 30year longitudinal study in New Zealand. Child Abuse \& Neglect 37 (9): 664-74. https://doi.org/10.1016/j.chiabu.2013.03.013

Fernandez, C. A., Christ, S. L., LeBlanc, W. G., Arheart, K. L., Dietz, N. A., McCollister, K. E., Fleming, L. E, Muntaner, C., Muennig, P., \& Lee, D. J. (2015). Effect of childhood victimization on occupational prestige and income trajectories. PloS One 10 e0115519. https://doi.org/10.1371/journal.pone.0115519

Horsman, J. (2000). Too scared to learn: Women, violence, and education. Vol. 8. Thousand Oaks: Sage Publications, Inc. https://doi.org/10.4324/9781410604965 
Horsman, J. (2006). Moving beyond "stupid": Taking account of the impact of violence on women's learning. International Journal of Educational Development, 26(2), 177-188. https:// doi.org/10.1016/i.ijedudev.2005.07.023

Huang, L., \& Mossige, S. (2012). Academic achievement in Norwegian secondary schools: The impact of violence during childhood. Social Psychology of Education 15 (2): 147-64. https:// doi.org/10.1007/s11218-011-9174-y

Koss, M. P., Heise, L. \& Russo, N. F. (1997). The global health burden of rape. In Gender Violence, pp. 223-241. New York University Press: NY, NY. https://doi.org/10.1111/j.1471-6402.1994.tb01046.x

Kushmider, K. D., Beebe, J. E., \& Black, L. L. (2015). Rape myth acceptance: Implications for counselor education programs. Journal of Counselor Preparation and Supervision 7 (3). https:/ / doi.org/10.7729/73.1071

Lincoln, Y. S., and Guba, E. G. (1985). Naturalistic inquiry. Beverly Hills, Calif: Beverly Hills, California: Sage Publications, c1985.

Macmillan, R. (2000). Adolescent victimization and income deficits in adulthood: Rethinking the costs of criminal violence from a life- course perspective. Criminology, 38(2), 553-588. https://doi.org/10.1111/j.17459125.2000.tb00899.x

Madriz, E. (2000). Focus groups in feminist research. In Handbook of Qualitative Research (Norman K. Denzin, Yvonna S. Lincoln, Eds.) 2nd ed. p. 835-850.

McMahon, T. J. (2014). Child maltreatment and emerging adulthood: Past, present, and future. Child Maltreatment, 19(3-4), 135-144. https://doi.org/10.1177/1077559514555960

New York State Education Law. (1989). New York State Education Department, Office of the Professions. http://www.op.nysed.gov/training/camemo.htm

Olesen, V. (2011). Feminist qualitative research in the millennium's first decade. The Sage handbook of qualitative research, 129-146.

Ullman, S. E., \& Najdowski, C. (2009). Correlates of Serious Suicidal Ideation and Attempts in Female Adult Sexual Assault Survivors. Suicide And Life-Threatening Behavior, 39(1), 47-57. https://doi.org/10.1521/suli.2009.39.1.47

United States Department of Justice. (2003). National Crime Victimization Survey, 2003.

Weis, L., and Fine, M. (2000). Speed bumps: A student-friendly guide to qualitative research. Teachers College Press: NY.

Yuan, N. P., Koss, M. P. and Stone, M. (2006). The psychological consequences of sexual trauma. VAWnet, a project of the National Resource Center on Domestic Violence. Available at: https://vawnet.org/material/psychologicalconsequences-sexual-trauma.

\footnotetext{
i This research project was conducted under the guidance of State University of New York Distinguished Professor Lois Weis with Institutional Review Board (IRB) approval from the University at Buffalo.

ii Due to concern for the participants' emotional health and safety, the IRB limited the size of the focus group.

iii Thank you to the brave and generous women who participated in this study. All names presented are pseudonyms, and all other identifying information about participants has been altered to ensure confidentiality.
} 